\title{
Disrupting Colonial Mindsets: The Power of Learning Networks
}

\author{
Catherine McGregor \\ University of Victoria
}

\begin{abstract}
If changes that make a difference to Aboriginal learners are to be effected in public schools, then transformational change is required (Menzies, Archibald, \& Smith, 2004). How is transformational change best achieved? In this article, I argue, based on a recently completed study (McGregor, 2013) that teacher learning-particularly among nonAboriginal teachers - is critical to effecting transformation in how teachers think about Aboriginal learners as well as how they plan and deliver fully inclusive learning opportunities. After outlining a theoretical framework for transformation focused on networked, inquiry-based learning and culturally inclusive practices, I explore how one particular teacher-learning network - the Aboriginal Enhancement Schools Network (AESN) in British Columbia, Canada, offers a powerful example of how teacher learning networks can enable deep and transformational change among participating teachers and leaders. I provide exemplary stories of transformation to illustrate the power of this model to effect changes in teacher beliefs and mindsets about Aboriginal learners and culturally inclusive practices. Following this, I identify several key enabling features of the AESN, including socially just, distributed forms of leadership, relational accountability (Wilson, 2008), and affiliative, catalytic models of implementation, a focus on "new, strong and wise ways" (Halbert \& Kaser, 2012, p.11) of learning, and provincial and district resources that support network learning activity. The conclusion highlights implications of this study for school jurisdictions and policy makers.
\end{abstract}

Keywords: networked teacher learning; transformational change; socially just leadership 


\section{Disrupting Colonial Mindsets: The Power of Learning Networks}

There is a well-documented and significant problem in the public education system: its failure in meeting the needs of Aboriginal learners and their communities (St. Denis, 2010; Royal Commission on Aboriginal Peoples, 1996). Statistically, Aboriginal students do considerably less well in Canadian schools with significantly lower graduation rates (CCL, 2009). Educational jurisdictions across Canada have begun to take this challenge seriously and have adopted a range of policy strategies designed to address this concern, such as integrating Aboriginal content into existing curricula and developing local resources that integrate Aboriginal perspectives and ways of knowing into their programs (Batiste \&Youngblood Henderson, 2009). Yet there remain significant challenges: Among them, the reality that the majority of educators in the public school system are non-Aboriginal and naturalized colonial discourses and practices persist at the state, regional, and local levels. In this article, I discuss these phenomena through an exploration of a recently completed research study about a British Columbia (BC) initiative called The Aboriginal Enhancement Schools Network (AESN). This network, made up largely of non-Aboriginal educators, has been working with educational leaders and Aboriginal peoples committed to implementing a more holistic and inclusive approach to working with Aboriginal and non-Aboriginal learners. The article will describe how non-Aboriginal teachers committed to professionally focused inquiry and learning are developing their identities as allies with and among their Aboriginal colleagues, becoming culturally inclusive pedagogues, and learning how to work with Aboriginal communities and Elders. The article provides important evidence about the impact of the AESN in altering educators' beliefs about Aboriginal learning, pedagogy, and practice as well as how affilitative models of learning in networks are catalysts for effecting change. It exemplifies what a number of Aboriginal and non-Aboriginal scholars have documented-only when educators themselves are morally and professionally committed to inclusive practices, to embrace difference and reflect on their own complicity in historical and contemporary discourses of colonization and oppression, will education and schooling be transformed so as to affect Aboriginal learners inclusion and success (Baskerville, 2009; Brooke, 2012; Hodgson-Smith, 2000; Kanu, 2005; Regan, 2010). Drawing from a recently completed research study (McGregor, 2013), this article provides important evidence of how efforts addressed at transforming BC classrooms were initiated and supported through the AES Network, documents the conditions that supported these transformational processes, and maps out the challenges that remain. A discussion of existing scholarship focused on decolonizing, on culturally inclusive modes of teaching and learning as well as on the power of networked forms of teacher learning will be offered as a means of understanding how these successes were achieved, while identifying gaps that remain. Its conclusion will also briefly discuss policy implications for Canadian educational jurisdictions that arise from the study, including the need for renewed commitments by educational policy makers to effecting substantial changes in Canadian schools.

\section{Situating Myself as a Settler and Colonizer}

It is important that I begin by acknowledging my privileged position and credit my Aboriginal colleagues who have taught me much about how I can work as an Indigenist (Wilson, 2007) scholar, committed to unpacking and challenging the colonial relations 
and logics that endure in much academic research (Donald, Glanfield, \& Sterenberg, 2012). I am a white, lesbian, middle class woman, born in Canada, and I have been a visitor on the territories of the Lekwungen, Wsáneć, and Coast Salish peoples for most of my life. I also acknowledge that I work in the privileged location of a university setting in a faculty of education. My own anti-oppressive reflective practices have given me much to contemplate about my complicity as a settler and oppressor; my family history involves me in the colonial practices of "scooping" Aboriginal children from their onreserve families (common in the 1960s and 1970s in BC). While a teen at the time, this history has served as a catalyst for helping me to understand how colonialism continues to operate in daily life as well as deepening my understanding of my own complicity with these and other colonial discourses and regimes of truth. These understandings about my histories, my socio-political contexts, and myself makes it even more important that I work in ethically informed, relational ways (Wilson, 2008) when working within the field of Indigenous education. I am grateful to my Aboriginal colleagues and mentors who have provided me with opportunities to learn from and with them in coming to understand some of the challenges facing Aboriginal learners in the BC school system. This article reflects some of these learnings.

\section{Transforming Teacher Mindsets}

The ongoing cycle of First Nations education must be changed. Transformation of schooling and education is not merely a set of strategies related to changing learners' behavior, changing governance, and so forth. Political, economic, and social changes also need to occur in the wider community context. Transformation and how it is attained requires a critical and political understanding, and eventually commitment to act. (Menzies, Archibald, \& Smith, 2004, p. 1)

Transformation - and particularly transformation that leads to action-are critical to ensuring schools focus on how to create successful learning environments with and for Aboriginal learners. Teachers are key to effecting change, as Hattie (2009) seminally argued-"what teachers do matters"- and "it is some teachers with certain mind frames that make the difference" (2012, p. 18, italics added). The mindsets his research documents are learning and change centered - and so placing an emphasis on developing teacher mindsets that are focused on inquiry to better support student learning is a good way to start effecting changes in outcomes for Aboriginal students. Yet as Menzies, Archibald, and Smith (2004) noted above, there is much more at stake here-if conceptions of learning and what counts as success remains fixed in dominant, Eurocentric conceptualizations and the knowledges that matter remain fixed in grand colonial narratives, then the goal of transforming schools and classrooms will fall short. Their call for transformation suggests that teacher learning or inquiry processes must be framed in ways that make the political and historical contexts of education as a system of domination and control evident and then actions can be taken to dismantle them. In other words, teachers also need to learn about and inquire into the colonial roots of their profession, critically examine the past and present to become allies with Aboriginal peoples in effecting changes, which will make a difference for all learners. Taken together, these ideas suggest that transformation of teacher mindsets has at least two interrelated components: first, the need to transform teachers into inquiry-minded 
practitioners with learning at the center of their thinking, and secondly, to take the teacher-learner into new learning terrains that challenge and trouble their colonially bound thinking. The next section of this paper explores these concepts and the implications of these approaches in achieving transformational effects in Aboriginal education.

\section{How do Teachers Learn?}

While there are competing theories as to how adults learn, for the purposes of this article learning theories that emphasize how teachers engage in professional forms of learning will be highlighted. Of particular import are the learning theories of Lave and Wenger (1991) because they make clear the direct relationship between learning, professional communities, and identity formation. Why is this important? As Aoki (1991) famously posited, "The teacher is the teaching"; in other words, a teacher's beliefs and understandings are core to how he or she teaches and understands the processes of teaching and learning. Therefore, to effect change in teacher practice, one must alter teacher beliefs, how teachers think about their professional role or identity. Changing beliefs and understandings or the meanings teachers hold is learning, as Lave and Wenger (1991) argued. Learning is also a participatory activity, within and among communities of practice. In essence, while learning may be individually accomplished, it is always situated in the social and cultural; one therefore adopts, adapts, or "takes up" practices that are evident within a community of practice. This has significance if one thinks about professional learning communities, particularly in thinking about how processes of innovative or new learning might be initiated or maintained. Indeed, as Wenger (1998) described, a process of engagement,

around a joint enterprise is an ideal context for...leading-edge learning, which requires a strong bond of communal competence along with a deep respect for the particularity of experience. When these conditions are in place, communities of practice are a privileged locus for the creation of knowledge. (p. 214)

More will be said about the conditions for deep engagement and learning later in this article, but it is an important highlight in the context of thinking about networked learning, which I shall discuss next.

\section{The Power of Networked Learning}

While educational researchers have always been involved in thinking about how to best support professional learning among teachers, in the past decade there has been a noticeable shift in how teacher learning is both understood and conceptualized (Stoll Bolam, McMahon, Wallace, \& Thomas, 2006; Stoll, Robertson, Butler-Kisber, Sklar, \& Whittingham, 2007). Networking and networked forms of learning are key ideas that have come from this field of study. Networking has become a dominant concept in teacher learning (Timperley \& Alton-Lee, 2008; Stoll, Halbert, \& Kaser, 2012) and among school improvement scholarship (Levin, 2012; Leiberman \& Mace, 2009) conceptualized as a means to more effectively alter or innovate teaching practice and improve student success. Networking models are understood to be more powerful tools for learning, given that they create webs of connection (threads) among and between a range of sites (nodes) and individuals and groups, creating multiple, continuous, and 
simultaneous sites for learning. Networks compare favourably to other forms of teacher learning (Earl, Katz, Elgie, Ben Jaafar, \& Foster, 2006; McCormick, Fox, Carmichael, \& Procter, 2011; Stoll et al., 2007).

Conceptually, the idea of networked learning is closely aligned with the notion of communities of practice and learning, described earlier. Jackson and Timperley (2006, as cited in McCormick et al., 2011) suggested that networked learning includes four components: learning from one another, learning with one another, learning on behalf of other individuals in a school or team, and meta-learning - a way of learning about your own learning. Networks are also vehicles that can both sustain and incubate desired changes; this is particularly true when a professional network has a focus on a shared commitment, goal, or outcome. In other words, the network's purpose is a powerful lever for change to be both initiated and nurtured (Ritchie, 2012).

There are many ideas as to how networked learning can be enhanced. Stoll, Halbert, and Kaser (2012) emphasized the power of having shared foci, the importance of trusting relationships, engaging in collaborative forms of inquiry, and creating intentional connections between an inquiry team and other networks/communities of practice. BakerDoyle (2008, as cited in McCormick et al., 2011) emphasized informal supports achieved through "intentional professional networks" (p. 47) where strong ties between local participants and more distant professional allies created spaces for more diverse (and innovative) approaches to professional work. Strong and weak ties are also discussed by Mitchell and Sackney (2011). Strong ties in personal networks generally develop among educators with similar professional belief systems, providing a stable foundation and a safe environment for incremental change. Weak ties in personal networks, on the other hand, generally develop between educators from diverse backgrounds and professional belief systems and "provide a rich source for new ideas and possibilities as well as a foundation for experiments in practice" (p. 28). McCormick, Fox, Carmichael, and Procter (2011) also talked about the power of brokers, critical friends and linkers - all conceived of as supportive learning centered catalysts - in creating powerful and effective professional learning networks in which teaching practice is altered or changed.

As these authors illustrated, the key to a learning network is connectivity. However, when thinking about connectivity it is important to think not just about linking nodal activities or sites: connectivity in a learning network is also about personal and professional relationships developed through shared experiences. Learning networks can result in strong ties of trust when there is a focus on shared purpose and suggests that social-emotional engagement are necessary conditions for deep and impactful learning. However, it is also important to note that while teacher-learning networks can be formally established and structured, they are also emergent and affiliative. That is to say, while connections may be suggested or formalized through establishing roles and structures, much of the network develops from its engagement with processes of investigation, drawing upon different resources, individuals, groups, organizations or specific locations that are necessary to supporting the learning of network participants. 
In summary then, teacher-learning networks are tools that enable and enhance teacher learning, both individually and collectively. While often formally structured, they are also emergent, relational, affiliative, and context specific. While they are theorized as powerful tools for transformation of practice (and concomitantly, student success), their effectiveness in transforming or altering practice is also context and condition driven. Designs, structures, participants' interests and knowledge, and processes of engagement/connectivity can either enable or constrain new learning.

As the above discussion has intimated, there are important ways in which a focus on professional learning through networks can lead to significant and powerful changes for learners in schools, including Aboriginal learners. Such professional conceptualizations of teacher learning offer promise and serve as powerful pathways into how systemic transformation of schools and classrooms might be realized. Yet without a focus on the context and histories of Aboriginal peoples and attention to culturally inclusive practices and pedagogy, such processes, however well informed, may simply reiterate the status quo discourses, which privilege some knowledges and investigations over others. With this in mind, I turn to the question of how to decolonize naturalized thinking about learning and learners.

\section{From Colonial Paradigm to Culturally Inclusive Practices}

As was noted in the outset of this article, Aboriginal scholars and community members have long understood the power of naturalized colonial discourses in schools and educational systems. For Aboriginal scholars in education, this has resulted in a renewed, concerted effort to promote Aboriginal pedagogies and culturally inclusive practices (Hodgson-Smith, 2000). Aboriginal forms of learning seek to educate the mind, heart, and spirit in a holistic manner (Archibald, 2008). Another important component of an Aboriginal pedagogy is its relationality; that is, it emphasizes engagement with and among members of the wider cultural community (Rice, 2005; Williams \& Tanaka, 2007).

The challenge for schools with largely non-Aboriginal educators is to find ways of incorporating these ways of knowing, being, and doing into classroom practice. Some policy measures have been taken to support this work; for example, the BC Ministry of Education and Aboriginal scholars have jointly developed what are called "The First Peoples Principles of Learning" (2013), which are being used to guide curriculum development and other written documents. There is also a formal commitment to developing local Aboriginal Enhancement Agreements between local/regional Aboriginal peoples and individual school districts. The goal of these agreements is to focus educators' attention specifically on the successes of Aboriginal learners. More will be said about these agreements later in this article.

Policy measures aside, seminal scholarship has emerged that has focused on how to resolve the challenge of affecting the practices of non-Aboriginal educators. Many of these emphasize immersion experiences; this is because deep, transformational learning must be felt and performed in order to effect changes in beliefs as the brief discussion of Wenger's (1998) community of practice made evident. For example, Tanaka et al. (2007) described how undergraduate teachers were transformed through an Elder/carver-led, 
totem-pole-making experience. Bishop, Berryman, Wearmouth, Peter, and Clapham (2012) also reported on a long-term study in New Zealand where facilitators provided prompts and asked critical questions that caused teachers to challenge their assumptions about Maori learners, their culture and communities. Finally, Baskerville's (2009) selfstudy of her efforts to engage Aboriginal learners provided a powerful example of how cultural immersion was central to her personal transformation as a teacher. These studies suggest that teacher beliefs can be disrupted, particularly when teachers become immersed in Aboriginal cultures, contexts, and communities and when they critically examine their dominant ways of thinking. It also suggests that non-Aboriginal teachers can become what Wilson (2007) described as "Indigenist." Drawing from his work on building respectful research relationships between Aboriginal and non-Aboriginal peoples, an Indigenist approach to teaching would involve respecting, honouring, and acknowledging the perspectives and worldviews of Aboriginal peoples, culture, and knowledges; would place an emphasis on the social, historical, political, and cultural contexts of Aboriginal peoples; would recognize and acknowledge the colonial discourses that have shaped the traditional practices of schooling; and would place an emphasis on reciprocity in which teacher and learner roles can be reversed, accepting that knowledge is relational and flows among and between peoples.

While acknowledging the critical importance of these approaches in effecting change in teachers practice and the experiences of Aboriginal learners, there is also the reality of how teachers respond when faced with making such changes. Transforming teacher beliefs to interrupt and disrupt the comfort and familiarity of dominant professional practices and calling for an examination of one's own complicity with discourses of colonialism can be difficult, painful, and emotional work, but it is necessary for genuine transformation. For non-Aboriginal peoples who have lived their lives benefiting from their privileged colonial heritage, Regan's (2010) question is particularly relevant: "How will we do [this work]... in ways that speak to truth, repair broken trust, and set us on a transformative decolonizing pathway toward more just and peaceful relations with Indigenous people?" (p. 2). Regan (2010) rightly emphasized that this decolonizing work is our own as colonizers and cannot become the burden of Aboriginal peoples. However, equally as important are Boler's (1999) observations about how difficult, complex social justice issues that are centered in individual or collective beliefs about difference are subject to a "cultural construction of complex silences," which permit a "sanctioned avoidance of anxiety and fear, a socialized neglect of emotion" (Brookes, 2011 p. 52). The world of teaching and the discourses of teacher professionalism are heavily implicated in creating and maintaining cultures of complex silences around Aboriginal education: How can spaces be created in which these discomforts and silences can be experienced, successfully interrogated, and revealed for what they are? In such moments and spaces of vulnerability, transformation can emerge.

\section{Documenting Changing Practices Among Non-Aboriginal Teachers}

As the introduction to this article noted, the AESN was created as a means of altering teacher beliefs and practices in working with Aboriginal students and in addressing Aboriginal student success. In total, about 75 schools and approximately 400 teachers, teacher leaders, and school principals from across British Columbia are involved in the AESN. Some of the AESN members are of Indigenous descent; others declare as Status 
Indians, urban Aboriginals, mixed race Aboriginal people, or Métis, with the remaining members largely White.

The sections that follow draw from a study completed in 2013 that documented the effectiveness and impact of the AES Network. ${ }^{1}$ The study was collaboratively developed with the AESN Advisory Board; it involved site visits, interviews, focus groups, and document analysis. The research team also invited participants to share stories of impact: Stories became the primary means through which data was collected and represented. This was done to ensure the process respected Aboriginal knowledge and ways of knowing and teaching, while authentically representing the scope and depth of impact. More than 50 AESN participants were included in the analysis. The analysis was conducted in several ways and codes were developed following a shared process of data analysis with members of the AESN Board, the researcher, and her assistant. Themes were created from this initial coding and these themes, once developed, were shared with the Board to ensure the themes reflected their understandings of primary impact. While a full discussion of this report goes beyond the scope of this article, I draw from its findings to illustrate the ways in which the AESN enabled the transformation of non-Aboriginal teachers who worked within this network.

\section{The Aboriginal Enhancement Schools Network (AESN)}

The AESN is a professional learning network for teachers, principals, vice principals, and support professionals who are employed in BC's public schools, and includes both Aboriginal and non-Aboriginal educators. It has been in operation since 2009. The idea of creating this particular network structure came from the BC Ministry of Education, Aboriginal Education Branch; the goal was to involve teachers, principals, and other education professionals in a structure that specifically focused on Aboriginal student achievement, outcomes emphasized in locally negotiated Aboriginal Enhancement Agreements (AEAs). The AESN model built upon an existing teacher network-the Network of Innovation and Inquiry (NOII) that has been operating in BC since 2001 under the leadership of Drs. Linda Kaser and Judy Halbert, its principals.

The purpose of the AESN is to improve learning results for Aboriginal learners and to increase understanding of Aboriginal cultures and histories for all learners. The Network is designed to build the capacity of teachers and principals through processes of inquiry informed by current research, including Aboriginal knowledges and pedagogy, with an emphasis on classroom-based performance assessment as a means for tracking success. The AESN has four major components:

- an annual cycle of inquiry at the individual level connected to the collaboratively developed Aboriginal Enhancement Agreements;

- regional meetings to share resources, research, and findings;

- aubmission and publication of inquiry reports; and

- $\quad$ public sharing of such reports at regional and provincial forums. 


\section{The Structure of the AESN}

The structure of the AESN is modeled on its successful predecessor, the NOII. Understanding this structure is important to analyzing the extent of its impact on affecting or altering educators' mindsets. The central purpose of the NOII/AESN Networks is to shift teacher and/or Network members' thinking from that of teaching and learning in order to sort learners (assessment to compare and rank students) to that of a learning centered system (Kaser \& Halbert, 2009). Learning then becomes the dominant paradigm, not just for students in classes, but also for the teachers engaged in inquiries. The shift to seeing the teaching-self as a learner is foundational to finding pathways for transformation of mindsets.

The Network structure utilizes a team-based approach; members work with others in their school, including their school principal or vice-principal or non-teaching professionals in developing an inquiry question for a year-long effort to improve the success of their students. Ongoing meetings and discussions with colleagues and partners in the inquiry are encouraged; formal meetings are built into the model (2-3 per year), and at least one regional meeting of inquiry teams from a particular geographical zone is held where investigations can be shared. One large provincial meeting is also scheduled in May of each year in Vancouver. These large scale events typically highlight the work of individual regional teams but also provide opportunities to explore conceptual ideas that will help teachers think more deeply about Aboriginal and non-Aboriginal student learning, characterized as an approach which emphasizes "walking together" (Kaser \& Halbert, 2011, p.8). Finally, all teams must write up a summary of their inquiry, which is submitted to the NOII/AESN principals for inclusion on the website, which makes it accessible to other Network members to use as a resource for current and future inquiry work. At the end of this process, each team is awarded a small grant; schools use such funds to purchase resources, fund release time, or attend professional conferences.

\section{Stories of Impact}

The nature of transformation can be difficult to document; as described earlier, one method used to trace impact and transformation was the collection of individual, written narratives. While a variety of methods were used to collect data, the narratives collected from AESN participants provide the strongest evidence of transformation. In this section, I provide four narrative exemplars collected from AESN participants that highlight the power of networked learning for transforming teacher understandings about Aboriginal students, families, and communities. This will be followed by a discussion of key attributes of the network that enable such transformational experiences.

\section{Story 1}

In all of the AESN inquiries...we have sought to make our students visible by developing their voices in the learning community. We have worked to build language skills, social emotional learning (sense of self), and a connection to the "big ideas" in traditional Aboriginal knowledge. We have seen measurable improvements in reading and writing skills, and we have observed the building of self-confidence when we have participated in an inquiry that focuses on all members of the learning community, students, and adults. We wanted our students to be heard and listened to with respect.... Our strategies 
matured as we developed our understandings of what our data, based on the $\mathrm{BC}$ Performance Standards, was telling us. Our students were improving in oral language skills, reading, and writing. They were becoming more familiar with Aboriginal ways of being that they experienced through reading literature about traditional ways and by Aboriginal authors, and we were doing a good job of embedding literature throughout the curriculum but the learning was lacking the authenticity that we wanted to provide....

We moved forward, developing individual research projects around heritage with our Grade 1/2 students with the intent of developing a sense of pride, awareness of heritage, and the ability to share a strong sense of self with a varied audience. The project involved asking family members questions, recording answers, and gathering important mementos to their life. Through this opportunity, we made a connection with members of the [unnamed] Reserve, and with other members of the Aboriginal community. The adult learners felt that they had a better understanding of who each learner was, the students were beginning to share their voice. (non-Aboriginal teacher narrative, February 2013)

\section{Story 2}

Doing a research question for the AESN allowed me to see that learning is not easily measured and that learning for students needs to be from the student's perspectives and from their families not from the perspectives of the vocal (Non-Native) professionals who have nothing invested in the community and stay a very short time. I also learned that when we have non-native teachers (I am not native) the teachers need to learn to take a wider perspective on learning not just a focus on aspects of academic learning that are easily measured, look good, sound good so the non-native educator can leave... If I had not participated in the AESN I would not have focused on a specific aspect of student learning. By focusing on a specific question, I had my eyes opened to the injustices that are still happening in our small rural schools that enroll First Nation's students. I personally believe that the lack of support our governments are giving schools enrolling mostly First Nations students is equally to that of Residential Schools. (non-Aboriginal teacher narrative, February 2013)

\section{Story 3}

I became involved in the Network of Performance Based Schools about nine years ago. I was inspired by the passion and knowledge of the [network principals] and by the dedication and curiosity of the others participating in the network. My level of involvement changed over the years, sometimes increasing and sometimes decreasing, depending upon available time and resources, but I continue to be inspired and challenged by the leaders and participants of the network... My participation also taught me that I wasn't alone in challenging current beliefs and attitudes and, thus, gave me the courage to continue to ask important questions and explore "better" ways of doing things. As I grew in my understanding of inquiry, unknowingly I was bringing some of my colleagues along with me. Through informal conversations, they witnessed my practise and were inspired to examine their own. We were no longer evaluating methods or approaches as good or bad but instead were wondering, tweaking, applying, revising, sharing, and wondering some more. I have really appreciated the message that bigotry can manifest itself as low expectations for our First Nations students. As a First Nations 
woman, having this message stated clearly by non First Nations educators has been very powerful. I have witnessed educators examine their practice and ask themselves if in fact they have perpetuated this destructive pattern. I have also walked alongside teachers as they begin the journey to doing things differently. These teachers are all good, hardworking, well-intentioned teachers... I believe "we are smarter together." I have benefitted greatly from networking with others.... Networking is a vital part of this community and I am grateful to have the opportunity to participate. (Aboriginal teacher narrative, March 2013)

\section{Story 4}

This year, we have many forces driving extraordinary learning for staff and students: The AESN Network Inquiry team, NOII inquiry team, School District Inquiry Team, and my Humanities 9 Inquiry are asking, "What can the canoe teach us about who we are as Canadians, where we live, how we express ourselves, and who we want to become as Canadians? What aspect of the canoe will guide your future?" This question caught the imagination of our Aboriginal support educators. Each felt that they could support student learning by attending classes; by presenting on topics such as Residential Schools, Harper's apology from Canadians, paddles, and art projects on paddles and decorating; and by having an Elder tell us more about the canoes of the West Coast. We are a team! Each of us has connected with various students as they each learn about local Indigenous art, culture, geography, and issues around sustainability. Without the formal AESN and NOII inquiry, I wonder if we would have had such an engaging way to work together.

It starts out slowly, with each of us finding out who we are and why we are doing what we do, and once we see our students connected and open to discussing Aboriginal history in Canada, boundaries, and see suspicions leave, we each simply work to learn more.... Each of us often says that we do not know. Each of us is searching for more information and students see us modeling learning and grieving at what has been lostand yet searching and finding other resources.... We are pulling together in our canoe and learning about who we are, where we live, how we express ourselves, and what we want to become! As educators, we will use the aspect of inquiring together to learn more about our students, our Aboriginal culture, and ourselves. (non-Aboriginal teacher narrative, March 2014)

\section{The Power of AESN Learning: Key Features}

In my impact assessment of the AESN, I documented a number of critical features that have assisted the transformational growth of teachers who participate; however, for the purposes of this article, I will draw on two central features that are also evident in the stories above. First, the importance of socially just leaders and leadership, and secondly, the catalytic, affiliative spaces created through networking in which transformational learning is enabled.

\section{Socially Just Leaders and Leadership}

As the above stories and assessment of the AESN made evident, a number of key leaders - both Aboriginal and non-Aboriginal — set out to build an inquiry network focused on creating schools and pedagogical practices that were socially just and 
inclusive of Aboriginal ways of knowing and being. These initial leaders were powerful models for network participants as the stories above illustrate. Yet the AESN principals envisioned and modeled leadership in a number of important ways: as distributed, nonhierarchical, reflective and anti-oppressive, and relational. Foundational to the network structure, the model of collaborative inquiry sought to engage teachers in actions that would alter their practices, deconstructing traditional Western ways of envisioning teaching and student success. This is an important component of leadership: Drawing from the goals of the Aboriginal Enhancement Agreements, every leader is continually asked to examine the question, "How does my inquiry, my practice, better enable Aboriginal learner success?" Distributed forms of leadership were emphasized as team leaders were recruited from various regions around the province. Importantly, Aboriginal leaders were core to the Network's regular activities, providing exemplars to its members of what it means to engage in anti-oppressive and culturally inclusive educational practice. The Network was also used to identify and support emerging teacher leadersso that those who were engaged in inquiries that exemplified the struggle to make colonial educational practices visible were recognized and their learning histories shared in multiple settings - provided positive catalysts for how change might be achieved. The open sharing of what it means to be an adult, life long, critically engaged learner was also explicit; such learning centered leadership practices were core to formal Network activities at the regional and provincial level. Just as importantly, critical forms of selfreflection were built into Network leaders meetings and communications so that the process of inquiry-based learning became part of their personal and professional leadership practice. As Sachs (2003) suggested, the leaders in the network are activist professionals: "The activist teacher professional creates new spaces for action and debate, and in so doing improves the learning opportunities for all of those who are recipients or providers of education" (p. 153, italics added). As such, they create powerful conditions in which transformation can take root.

\section{Network Relationality: Creating Catalytic, Affiliative Spaces}

In my earlier discussion, the important role of leaders is highlighted, particularly how modeling and engaging in socially just, learning-centered inquiry provides exemplars and catalysts for effecting change. Yet leaders and leadership are not enough; important features of the network emerge from the structures and processes of networked learning and inquiry that enable transformation. These include regular formal and informal processes of sharing and engaging network members in dialogue that allows space for scaffolding teacher understandings, an emphasis on research-theories and approaches that have grounding in best evidence of what works in supporting diverse learners, and finally, time and resources for ongoing engagement and relationship building.

Relationality is key to what I witnessed in describing the power and impact of the network on teacher learning, particularly learning focused on questioning one's own practice and approach to working with Aboriginal learners. As I noted earlier in this paper, shifting long-held beliefs that are the product of historical discourses and institutional practices that have long been privileged in Western educational systems is difficult work. There is personal and professional risk in such activities: So having a network of colleagues who can help to navigate such efforts in safe spaces becomes 
critical to effecting change. The more than 15 interviews conducted for the impact AESN assessment repeatedly brought to the fore the importance of trust and relationships in engaging in work that matters deeply for Aboriginal learners, while simultaneously implicating the teaching self or identity in such inquiries. Navigating the complex terrain and silences around Aboriginal education is deeply important to both Aboriginal and nonAboriginal teachers - its historical, cultural, political, and social roots require new trajectories of action and engagement, a path in which travelling together is possible in search of new and renewed futures. This is a critical point to emphasize: Travelling together emerges in relationally informed cultures in which both Aboriginal and nonAboriginal peoples learn with one another. Nieto (2008), in her discussion of how to create liberatory cultures, argued that such decolonization practices promote "a new social order in which...co-operation and solidarity in interpersonal relations predominate" (p. 141). Rice (2005) buttresses this call for collective, deconstructive work when he talks about the value of bringing Indigenous perspectives into curriculum, arguing that "people who belong to a traditional culture and those who do not have a common need for the values and truths taught in these teachings" (p. 55). The stories included in this article begin to make clear the deep trust that can emerge from long term, continual work built on shared commitments to change, when enacted among and with like-minded colleagues, Indigenous peoples, and leaders within a network, always becoming, through deeply transformational learning practices, more culturally responsive and inclusive educators. In the cases provided in this article, taking this relational and Indigenist approach (Wilson, 2007) provides evidence that teacher mindsets are being altered and transformed. In sum, the Network has enabled the creation of collaborative, generative spaces in which to learn together.

\section{New, Wise, and Strong Ways of Learning}

Halbert and Kaser (2012) articulated the need for research informed innovation in their book Spirals of Inquiry. Described as "new, wise and strong ways" (p. 13) they documented how networked inquiry and learning is guided not only through the investigation of one's own professional practice, but also informed by valued educational research. They highlight the following three knowledge paradigms: new-innovative and emerging educational practices; strong-enduring educational practices that have evidence to support their continued use; and wise-Aboriginal knowledges and practices that support diverse, inclusive, and holistic forms of learning. Each of these paradigms is integrated into Network activities as a part of the annual cycle of knowledge sharing and learning. It models for teachers the realms of knowledge they should access in designing, implementing, and assessing their school level inquiries. This is an important component of Network activity, as it provides a space in which to honour and value the work of Aboriginal scholarship and legitimizes its inclusion as a valued knowledge source for teacher thinking, teacher practice, and teacher learning. Without this attribution of value to the work of Aboriginal scholarship, the legitimacy of this approach could be questioned; instead, throughout the impact-assessment research investigation, teachers, leaders, and district staff repeatedly drew on Aboriginal scholarship as sources to situate and legitimize their inquiries into Aboriginal student success and learning. 


\section{Resources for Shared Learning}

Finally, I would be remiss if I did not highlight the ways in which the Network offers resources and funding for AESN members. While the level of funding is smallwith inquiry teams receiving an annual $\$ 500.00$ grant if they participate and file a summary report at the end of each cycle of inquiry they complete-teachers and formal leaders alike have all highlighted the value this affords inquiry groups who can use these funds to purchase additional resources, purchase goods or services, or fund in-service, professional development or travel. The real value of such funds is how they are used to secure additional resources at the school or district level and how these additional funds enable new network activity to thread its way into additional sites where transformation then becomes possible. The impact assessment traces how districts that embraced inquiry learning that focused on Aboriginal student learning engaged larger numbers of teachers and were becoming cultures of innovation and transformation. The simultaneous efforts to support emerging leadership in Aboriginal education and provide resources to accelerate its impact make evident the potentiality for transformational sites and practices to flourish province wide.

\section{Implications for School Districts and Provincial Policy Makers}

Districts who have valued inquiry and teacher leadership in Aboriginal education have made significant headway into shifting cultures so as to engage non-Aboriginal teachers in work that is both understood and perceived as valued. Indeed in these districts, Aboriginal teachers in particular expressed that this recognition gave them permission to engage more deeply in inquiries in their schools and district, to take on roles of teacher leadership in order to promote culturally inclusive teaching practice and to engage community members and non-Aboriginal colleagues alike in shared experiences of learning. This affiliative model-built in collaborative teams, drawing from existing strengths within the established teaching force, supplemented by the enabling features of local knowledge and contexts - has positioned them to grow into highly impactful spaces in which student learning, both Aboriginal and non-Aboriginal, has significantly grown. In the context of this study, the culture of learning within numerous school districts has become ubiquitous and more teachers have become primed to engage in thinking more critically about their own educational practices, and about how patterns of colonial thinking can be interrupted.

Networked forms of learning offer potential to districts interested in creating professional cultures committed to innovation and equitable teaching practices that allow all learners to succeed. However, it is not the Network framework alone that accomplishes this work; despite its strengths in promoting change, it is only when this work is valued, recognized, and modeled so that it becomes the norm that challenges and critically examines naturalized ways of talking, thinking, and working with Aboriginal populations, that larger numbers of non-Aboriginal teachers will perceive the need for change. Finally, transformation cannot be assumed; as this article has attempted to illustrate, new learning needs to be seeded by knowledge of enduring and emerging best practices so as to provide positive models that can shape and alter existing teacher beliefs about the normative assumptions that often characterize learners from marginalized groups as low-achieving based on Western norms of performance and educational 
purpose. It also requires allyship: a commitment to working with Aboriginal colleaguesthe relational accountability and Indigenist perspective Wilson $(2007 ; 2008)$ described can provide the conditions and opportunities to "walk together" (Kaser \& Halbert, 2011, p. 4), to learn and authentically respond in meaningful and culturally appropriate ways. When districts consistently model this form of educational engagement, it becomes part of professional norms, and helps to create the impetuous necessary for non-Aboriginal teachers to deconstruct their own complicity in discourses of difference and marginalization.

\section{Concluding Thoughts}

In this article, I have taken an approach that has sought to tease out elements of what it means to engage non-Aboriginal teachers through networked forms of inquiry through the AESN framework, arguing that there are particular conditions that can be put into place in order to support creating cultures of innovation that decolonize educational spaces in schools. It is evident that there has been significant transformation of many teachers' thinking. It parallels much of what Aboriginal and non-Aboriginal scholars have argued are needed if we are to effect changes in schools and improve the quality of education and the success of Aboriginal learners.

Despite having taken this analytic approach, I recognize that in doing so, it might imply there is a particular pathway to creating environments that supports innovation and transformation. I would be remiss if I did not emphasize that the complexity of local contexts, histories, and patterns of relationality that have supported some districts' efforts to nurture their teachers commitments to culturally inclusive pedagogy and practice, or in other words the change trajectory, needs to be seen as organic and emergent, rather than the result of a single common plan. I have named this dynamic catalytic affiliation because there are catalytic features such as Indigenist leadership and a deconstructive mindset, and affiliative because actions are always relationally based and contextually specific. What I hope can be taken from this discussion is that we can, and should, attend to the conditions and potentiality of networked learning environments that enable such transformational approaches.

I have also emphasized how some school districts in $\mathrm{BC}$ have created positive change conditions using networked and inquiry-based learning models. But this observation needs to be extended beyond district boundaries and offers lessons for provincial policy makers and Departments of Education throughout Canada. There is promise in this regard in the current work of the BC Ministry of Education, which has embraced planning and implementation models that provide flexible frameworks for districts to engage in self-directed transformation and innovation. Such processes that build on the recognition of existing knowledge, expertise, and district capacity to engage in deep inquiry that is focused on inclusivity, and quality teaching and learning are beginning to having a profound impact on the ways in which districts, schools, leaders, and teachers explore their practices, their educational systems, and their work with Aboriginal learners. Clearly more research needs to be done to document how these approaches enable change, but the efforts to collaboratively engage districts, leaders, and teachers in practices that can transform and alter pre-existing teachers' understandings 
and beliefs is on a positive trajectory, emerging from the initial work of the AES Network. 


\section{References}

Aoki, T. (1991). Teaching as in-dwelling between two curriculum worlds. In Inspiriting curriculum and pedagogy: Talks to teachers, Monograph No. 12, Curriculum praxis (pp. 7-10). Edmonton, AB: University of Alberta Press.

Archibald, J. (2008). Indigenous storywork: Educating the heart, mind, body, and spirit. Vancouver, BC: UBC Press.

Baskerville, D. (2009). Navigating the unfamiliar in a quest towards culturally responsive pedagogy in the classroom. Teaching and Teacher Education, 25(3), 461-467.

Battiste, M., \& Youngblood Henderson, J. (2009). Naturalizing Indigenous knowledge in Eurocentric education. Canadian Journal of Native Education, 32(1), 5-18.

BC Ministry of Education. (2013). First Peoples principles of learning. Retrieved from http://www.bced.gov.bc.ca/abed/principles_of_learning.pdf

Bishop, R., Berryman, M., Wearmouth, J., Peter, M., \& Clapham, S. (2012). Professional development, changes in teacher practice and improvements in Indigenous students' educational performance: A case study from New Zealand. Teaching and Teacher Education, 28(5), 694-705.

Brooks, J. (2011, Winter). Bearing the weight: Discomfort as a necessary condition for "less violent" and more equitable dialogic learning. The Journal of Educational Foundations, 25(1-2), 43-62.

Boler, M. (1999). Feeling power: Emotions and education. New York, NY: Routledge.

Canadian Council on Learning (2009). The state of Aboriginal learning in Canada: A holistic approach to measure success. Ottawa, ON: CCL. Retrieved from http://www.ccl-cca.ca/pdfs/StateAboriginalLearning/SALFINALReport_EN.PDF

Donald, D., Glanfield, E., \& Sterenberg, G. (2012). Living ethically within the conflicts of colonial authority and relationality. Journal of the Canadian Association for Curriculum Studies, 10(1), 53-76.

Earl, L., Katz, S., Elgie, S., Ben Jaafar, S., \& Foster, L. (2006). How networked learning communities work, Volume 1 - The report. Aporia Consulting Ltd. Retrieved from http://networkedlearning.ncsl.org.uk/collections/network-researchseries/reports/how-networked-learning-communities-work.pdf

Halbert, J., \& Kaser, L. (2012). Spirals of inquiry: For equity and quality. Vancouver, $\mathrm{BC}$ : BC Principals and Vice Principals Association.

Hattie, J. A. C. (2009). Visible learning: A synthesis of over 800 meta-analyses relating to achievement. New York: Routledge.

Hodgson-Smith, K. (2000). Issues of pedagogy in Aboriginal education. In M. Brant Castellano, L. Davis, \& L. Lahache (Eds.), Aboriginal education: Fulfilling the promise (pp. 156-170). Vancouver, BC: UBC Press. 
Kanu, Y. (2005). Decolonizing Indigenons education: Beyond culturalism, toward postcultural strategies. Canadian and International Education, 34(2),1-20.

Kaser, L., \& Halbert, J. (2009). Leadership mindsets: Innovation and learning in the transformation of schools. New York, NY: Routledge.

Kaser, L., \& Halbert, J. (2011). Walking together for a better future. Adminfo, 23(3), 3-8.

Lave, J., \& Wenger, E. (1991). Situated learning: Legitimate peripheral participation. Cambridge, MA: Cambridge University Press.

Levin, B. (2012). System-wide improvement in education. UNESCO Report. Paris, France: IIED \& IAE

Lieberman, A., \& Mace, D. H. P. (2008). Teacher learning: The key to educational reform. Journal of Teacher Education, 59(3), 226-234. doi: $10.1177 / 0022487108317020$

McCormick, R., Fox, A., Carmichael, P., \& Procter, R. (2011). Researching and understanding educational networks. New York, NY: Routledge.

McGregor, C. (2013). Aboriginal inquiry: Lifting all learners. An impact assessment of the Aboriginal Enhancement Schools Network (AESN). Retrieved from http://inquiry.noi.ca

Menzies, C., Archibald, Q., \& Smith, G. (2004). Editorial: Transformational sites of Indigenous education. Canadian Journal of Native Education, 28(1-2), 1-7.

Mitchell, C., \& Sackney, L. (2011). Profound improvement: Building capacity for a learning community (Contexts of learning), (2nd ed.). New York, NY: Routledge.

Nieto, S. (2008). Chapter 9: Culture and education. Yearbook of the National Society for the Study of Education, 107(1), 127-142. doi: 10.1111/j.1744-7984.2008.00137.x

Regan, J. (2010). Unsettling the settler within: Indian residential schools, truth telling, and reconciliation in Canada. Vancouver, BC: UBC Press.

Rice, B. (2005). Seeing the world with Aboriginal eyes: A four directional perspective on human and non human values, cultures and relationships on Turtle Island. Winnipeg, MN: Aboriginal Issues Press.

Ritchie, S. (2012). Incubating and sustaining: How teacher networks enable and support social justice education. Journal of Teacher Education, 63(2), 120-131.

Royal Commission on Aboriginal Peoples. (1996). Report on the Royal Commission on Aboriginal Peoples: Volume 3: Gathering strength. Retrieved from http://caid.ca/Vol_3_RepRoyCommAborigPple.html

Sachs, J. (2003). The activist teaching profession. Philadelphia, PA: Open University Press.

St. Denis, V. (2010). A study of Aboriginal teachers' professional knowledge and experience in Canadian schools. Ottawa, ON: Canadian Teachers Federation. 
Stoll, L., Bolam, R., McMahon, A., Wallace, M., \& Thomas, S. (2006). Professional learning communities: A review of the literature. Journal of Educational Change, 7(4). doi: 10.1007/s10833-006-0001-8

Stoll, L., Halbert J., \& Kaser, L. (2012). Deepening learning in school-to-school networks. In C. Day (Ed.), International handbook of teacher and school development (pp. 1-27). London, UK: Routledge

Stoll, L., Robertson, J., Butler-Kisber, L., Sklar, S. \& Whittingham, T. (2007). Beyond borders: Can international networks deepen professional learning community? In L. Stoll, \& K.S. Louis (Eds.), Professional learning communities: Divergence, depth and dilemmas (pp. 63-76). Maidenhead, UK: Open University Press.

Tanaka, M., Williams, L., Benoit, Y., Duggan, R., Moir, L., \& Scarrow, J. (2007). Transforming pedagogies: Pre-service reflections on learning and teaching in an Indigenous world. Teacher Development, 11(1), 99-109.

Timperley, H., \& Alton-Lee, A. (2008). Reframing teacher professional learning: An alternative policy approach to strengthening valued outcomes for diverse learners. Review of Research in Education, 32 (Chapter 10), 328-369. doi: 10.3102/0091732X07308968

Wenger, E. (1998). Communities of practice: Learning, meaning and identity. Cambridge: Cambridge University Press.

Williams, L., \& Tanaka, L. (2007). Schalay'nung Sxwey'ga: Emerging cross-cultural pedagogy in the academy. Educational Insights, 11(3). Retrieved from http://www.ccfi.educ.ubc.ca/publication/insights/v11n03/articles/williams/william s.html

Wilson, S. (2007). Guest Editorial: What is an Indigenist research paradigm? Canadian Journal of Native Education, 30(2), 193-195.

Wilson, S. (2008). Research is ceremony: Indigenous research methods. Winnipeg, MB: Fernwood.

\section{Endnotes}

${ }^{1}$ The AESN Impact assessment (2013) entitled Lifting All Learners: An Impact Assessment of the AESN was funded by the federal government, Office of Indian Affairs. A copy of the complete report can be accessed from: http://inquiry.noii.ca/ 